\title{
GEOLOGIA DA CHAPADA DOS PARECIS, MATO GROSSO, BRASIL
}

\author{
SETEMBRINO PETRI* E VICENTE JOSE FULFARO**
}

\begin{abstract}
The Parecis Plateau separates the Amazonas basin from the La Plata River basin, and thus is one of the most important watersheds in South America. It is made up of the Parecis Formation that lies in unconformity upon the Early Cretaceous Tapirapua Basalt and crystalline rocks of Pre-Silurian age. The Parecis Formation begins with fine sandstones having an abundant clay matrix, followed by fine-to-medium grained, cross-bedded sandstones. To the south, several levels of conglomerate enveloping clayey sandstone lenses represent the upper part of the Formation, which in the north comprises a thick cross-bedded sandstone sequence. The summit of the plateau is covered by Tertiary gravel deposits that unconformably overlie the Parecis Formation.

Directions of paleocurrents drawn from cross-bedding in the sandstones show a northward transport, which is also indicated by increasing thincknesses of the sandstone facies northward. The main source area for the whole formation would then be located to the south. The gravel deposits that rest in unconformity upon the sandstones show a paleocurrent directed to the south, based on pebble orientation and on the distribution of sedimentary bodies resembling old fanglomerates.

An idea of the tectonic and paleogeographic evolution of this area may be obtained from these facts and also from knowledge of the stratigraphic column of the adjoining Parana sedimentary basin. In the Late Cretaceous, fluviatile sedimentation was going on throughout the Parecis and Paraná basins, which were separated by an arch, here named the Paraguay Arch, made up of Pre-Silurian metamorphic and sedimentary rocks of the Alto Paraguay and Cuiabá Groups. This arch is a great continental N-S tectonic structure separating two cratonic areas that is represented in the studied area by rocks of the Paraguay Geossyncline. To the south, this arch has a continuation through the N-S oriented Asuncion Arch, now tectonically depressed in a graben where olivine basalts $46 \mathrm{~m}$.y. old crop out.

During the Eocene the Paraguay Arch underwent downfaulting that also gave rise to the present geomorphic situation and the initiation of the Amazonas and La Plata River basin. Fanglomerate deposits formed along the southern flank of the Parecis Plateau, the newly formed watershed of these two great basins. At this time climatic conditions were probably semiarid. Climatic oscillations and base level changes led to the present situation with downcutting through the gravel deposits by streams of the Paraguay River basin.
\end{abstract}

INTRODUÇÃo A estratigrafía e a estrutura geológica da Chapada dos Parecis, norte do Mato Grosso, são aqui estudadas. Esta chapada constitui-se no divisor de águas das duas maiores bacias fluviais da América do Sul, as bacias do Amazonas e do Prata (Fig. 1).

O flanco sul da chapada é parcialmente formado por basaltos eocretáceos e o topo é constituído por depósitos cenozóicos. As encostas situadas entre os basaltos e a superfície de cimeira, que constitui o divisor, são ocupadas por sedimentos neocretáceos da Formação Parecis. Este complexo de rochas mesozóico-cenozóicas assenta-se sobre seqüências pré-cambrianas e eopaleozóicas, ocupando terras baixas e a chamada Província Serrana.

A região era, até data relativamente recente, desprovida de boas estradas e infestada de malária, dificultando o desenvolvimento de trabalhos geológicos que fossem além de reconhecimentos. Castelnau $(1850,1851$ e 1852) e Evans (1894) realizaram observações geológicas durante suas viagens. No século XX surgiram diversos trabalhos, iniciando com o de Campos (1909, in Almeida, 1964). Seguiram-se os de Oliveira (1915), Ab'Saber (1954), Almeida (1964), Oliveira (1964), Hennies (1966) e Guimarães (1971). Este último autor incluiu na Formação
Parecis arenitos eopaleozóicos e, portanto, sua discussão sobre a idade desta Formação foi prejudicada. Em data mais recente, equipes de geólogos da Companhia de Pesquisas de Recursos Minerais (CPRM) pesquisaram a área dentro do Projeto Aluviōes (Correa e Couto, 1972) e do Projeto Centro-Oeste. Os trabalhos que versam sobre a geologia regional das chapadas do interior do Brasil geralmente tratam os depósitos cretáceos apenas de passagem.

$O$ presente trabalho teve os seguintes objetivos: a) identificar mais precisamente as áreas de ocorrência das rochas cretáceas e cenozóicas da Chapada dos Parecis; $b$ ) sugerir, com os dados obtidos, possíveis ambientes geradores das formaçðes presentes; $c$ ) reconstruir paleocorrentes e, principalmente; $d$ ) estabelecer as prováveis relaçôes entre esses depósitos sedimentares e as bacias sedimentares do Amazonas e do Paraná.

Estudos sedimentológicos e estratigráficos foram realizados tendo em vista aqueles objetivos. Discutiu-se, também, a evolução tectônica da área, que esteve relacionada com o comportamento do Arco Central Paraguaio (Fig. 1), durante o Mesozóico e o Cenozóiço.

* Instituto de Geociências, USP - Caixa Postal 20899, CEP 01000 - São Paulo

** Instituto de Geociências e Ciências Exatas da UNESP - CEP 13500 - Rio Claro 


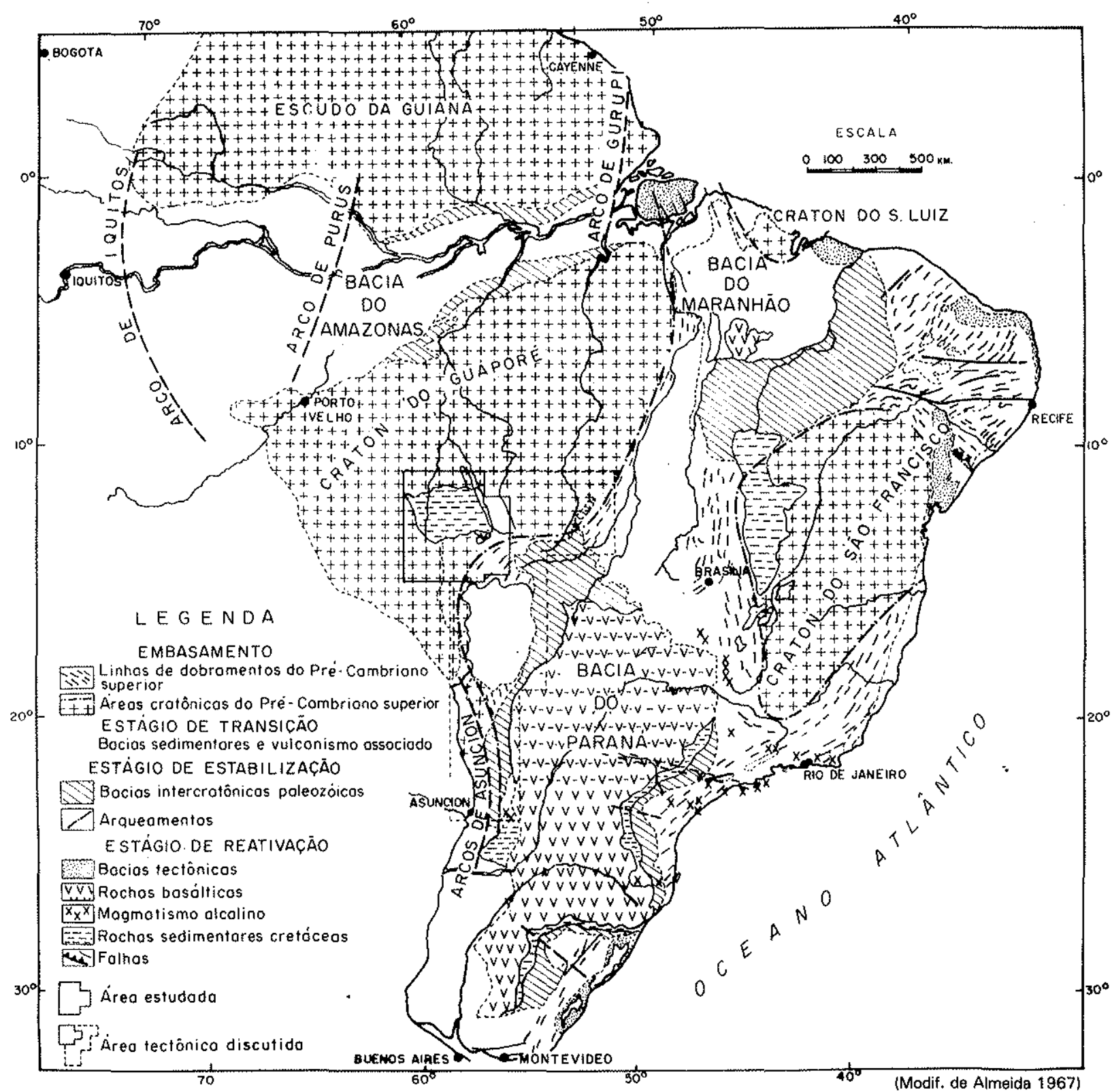

Figura 1 - Embasamento

LOCALIZAÇÃO DA ÁREA ESTUDADA A regiåo está localizada entre as latitudes de $11^{\circ}$ e $15^{\circ} \mathrm{S}$, e as longitudes de $56^{\circ}$ e $60^{\circ} \mathrm{W}$, que inclui a Chapada dos Parecis e áreas vizinhas. A Chapada, divisor de águas entre as bacias do Amazonas e do Prata, atinge $650 \mathrm{~m}$ de altitude. As cabeceiras do sistema fluvial do Rio Paraguai (pertencente à Bacia do Prata) descem pelos flancos meridionais da Chapada enquanto as cabeceiras do sistema fluvial do Rio Amazonas descem pelos flancos setentrionais. Os cursos de água do flanco sul são mais curtos e, portanto, dotados de nivel mais elevado de energia que os do flanco norte. A Chapada, portanto, é uma cuesta, mergulhando suavemente para o norte, e fortemente dissecada, de modo que as cabeceiras das duas maiores bacias hidrográficas da América do Sul estão, às vezes, separadas por distâncias de menos de $3 \mathrm{~km}$ (Fig. 2).

Os depósitos mesozóicos e cenozóicos são bruscamente interrompidos, no lado norte, ao longo da latitude de $11^{\circ} 30^{\prime} \mathrm{S}$, por um sistema de falhas, entrando em contato com o embasamento pré-cambriano do Craton de Guaporé (Figs. 1 e 2). Referências à ocorrência de rochas da Formação Parecis, ao norte dessa latitude, não foram confirmadas visto que tais rochas foram identificadas por Amaral (1974) como sedimentos arenosos eopaleozóicos e, como tal, aparecendo no mapa geológico do Projeto Centro-Oeste (Fig. 2). As rochas mesozóicas são limitädas, ao norte, pelo referido paralelo de $11^{\circ} 30^{\prime}$; a oeste se estendem pelo Território de Rondônia; e a leste atingem o meridiano de $54^{\circ} \mathrm{W}$.

Ao sul e a leste da Chapada dos Parecis estende-se a Província Serrana, formada por rochas eopaleozóicas exibindo amplos sinclínios e anticlínios dirigidos para NE-SW. As cristas correspondem às rochas mais resistentes dos anticlínios enquanto os vales correspondem aos sinclínios. Ao sul da Província Serrana estende-se a Baixada Cuiabana ocupada por rochas pré-cambrianas e me- 


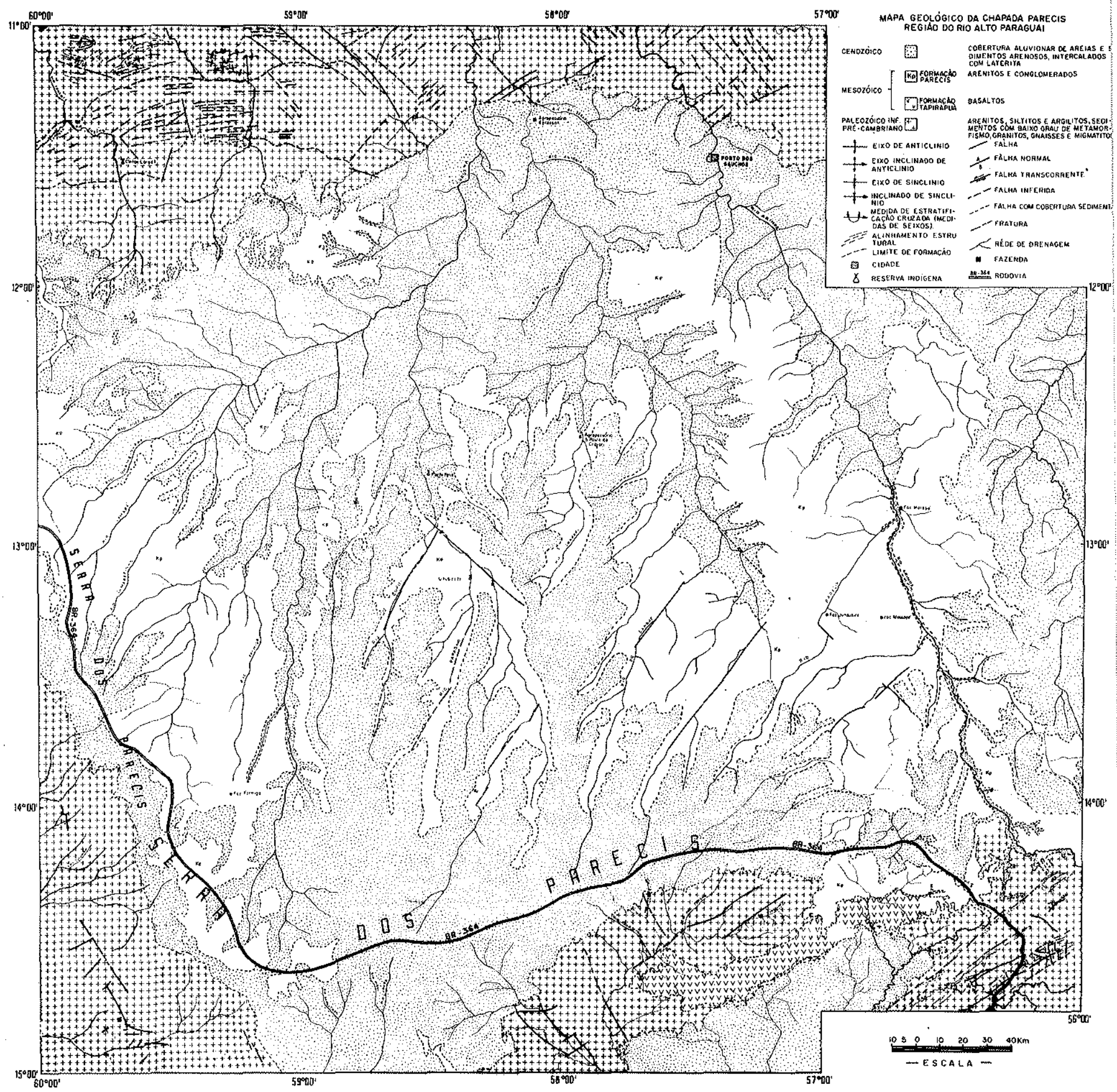


tamórficas eopaleozóicas. A Baixada Cuiabana passa para o Pantanal Mato-grossense, ao sul, constituído por extensas terras baixas que mergulham para o sul, onde atingem altitudes só de algumas dezenas de metros. $\mathrm{O}$ embasamento dos sedimentos quaternários que ocupam o Pantanal Mato-grossense situa-se abaixo do nível do mar.

Os basaltos eocretáceos ocupam a chamada Serra de Tapirapuã, que forma o degrau frontal do flanco sul da Cuesta dos Parecis. Os sedimentos neocretáceos dispóem-se acima dos basaltos em outro degrau, sendo cobertos pelos sedimentos cenozóicos que, por sua vez, são capeados por um ubíquo leito laterítico que ocupa o topo da Chapada. A geomorfologia da região reflete, portanto, a estrutura geológica.

O topo da chapada é plano e ocupado por vegetação secundária do tipo de cerrado que contrasta com a vegetação mais densa da área basáltica e de áreas ao norte, pertencentes ao sistema de drenagem do Amazonas. A floresta é provavelmente reliquia desenvolvida durante condições climáticas diferentes das vigentes hoje. Dunas de areia são largamente desenvolvidas na área de junção das rodovias BR-364 e MT-127, onde o Rio Juruena possui suas cabeceiras. Elas parecem ter sido recentemente estabilizadas, sendo ocupadas por incipiente e delgada cobertura vegetal. A estabilização do campo de dunas é motivado antes pela vizinhança da densa floresta equatorial das grandes reservas indígenas dos Parecis e Nhambiquara, que se estendem ao norte, do que mudanças locais das condiçőes climáticas. Regionalmente, flutuaçðes diárias de temperatura, bem acima de $10^{\circ} \mathrm{C}$, com noites frescas e dias quentes, a presença de uma estação seca e a composição arenosa das rochas são condições favoráveis ao desenvolvimento de dunas. A remoção da floresta favoreceria a expansão das dunas.

O topo da chapada está profundamente dissecado. Os sedimentos cenozóicos foram os mais afetados pela erosão, descobrindo sedimentos da Formação Parecis que afloram nos vales. A juventude desse processo é evidenciada pela presença de sedimentos recentes capeando os divisores.

ESTRATIGRAFIA A litostratigrafia da região foi descrita principalmente por Almeida (1964) que deu mais ênfase às rochas eopaleozóicas. Estas, que foram reunidas no Grupo Alto Paraguai, ocupam a maior parte do vale do Alto Paraguai, da Bacia do Prata e do vale do Rio Arinos, da Bacia do Amazonas. São pouco deformadas a oeste, aumentando as deformações para leste.

A coluna estratigráfica da região é a seguinte:

Terciário - Quaternário - Depósitos sem nome Discordância

Neocretáceo - Formação Parecis Discordância

Eocretáceo - Formação Tapirapuã Discordância

\section{Pré-Siluriano - Grupo Alto Paraguai Discordância}

Pré-Cambriano - Grupo Araras
Formação Diamantino

Formação Sepotuba Formação Raizama

Grupo Alto Paraguai Formaçäo Raizama Esta Formação consiste, de acordo com Correa e Couto (1972), em três litofácies: $a$ ) arenitos, arcósios e subarcósios passando, para cima, para arenitos predominantemente quartzosos e siltitos, e folhelhos subordinados. Arenitos conglomeráticos se intercalam na parte basal; b) ardósias amareladas colocadas acima da litofácies $a$; e c) a parte superior da Formação é constituída de arenitos de granulação média a grossa, com estratificaçðes cruzadas, estruturas gradacionais e estruturas de escavação e preenchimento. Estas sugerem ambiente fluvial como gerador desses sedimentos. A Formação aflora ao longo da rodovia Cuiabá - Santarém.

Formação Sepotuba Caracteriza-se por sedimentos finos. Folhelhos perfazem $70 \%$ da Formação. Subordinadamente, ocorrem arenitos, arcósios e siltitos. Ela aflora, em geral, nos núcleos dos anticlínios e, ao que parece, assenta concordantemente sobre a Formação Raizama. Seu limite ocidental corresponde, aproximadamente, ao traçado da rodovia Alto Paraguai - Nortelândia (Fig. 3). A espessura, de acordo com Hennies (1966), seria de $500 \mathrm{~m}$, mas Correa e Couto (1972) admitem espessura média de $3000 \mathrm{~m}$.

Formação Diamantino As litologias predominantes são folhelhos duros associados a folhelhos e siltitos micáceos finamente laminados. Localmente, como, por exemplo, em torno da cidade de Diamantino, ocorrem arenitos finos, avermelhados em leitos maciços. A Formação aflora entre Diamantino e Arenápolis (Fig. 3) e suas espessuras situam-se em torno de 400 a 500 m (Correa e Couto, 1972). Ela jaz, concordantemente, sobre a Formação Sepotuba. Muitos exemplos de estruturas de escavação e preenchimento e estratificaçðes cruzadas acanaladas são encontrados na rodovia que liga Diamantino à rodovia $\mathrm{BR}-364$, nas proximidades do contato com o Basalto Tapirapuã. A lenticularidade das camadas é bem visível nesses afloramentos. As estruturas sedimentares sugerem ambiente fluvial de sedimentação. Segundo Hennies"(1966), há gradual aumento da espessura da Formação em direção aos vales dos rios Cuiabá, Novo e Paranatinga, onde atinge espessuras de 2500 a $3000 \mathrm{~m}$. É possível, portanto, que nessas áreas o ambiente de sedimentação passe para marinho raso e, neste caso, a área Diamantino-Arenápolis seria não-marinha, marginal a este mar eopaleozóico. As três formaçð̌es parecem ser concordantes e, possivelmente, exibindo passagem gradacional. Correa e Couto (1972) notaram que os arenitos intercalados nos folhelhos da Formação Sepotuba são semelhantes aos da Formação Raizama, o que sugere relaçōes de interdigitação. As três formações representariam subambientes diferentes de uma plataforma instável e sincrônicas, pelo menos parcialmente.

Basalto Tapirapuã Este basalto, de natureza toleítica, cobre uma área de $350 \mathrm{~km}^{2}$, a oeste da cidade de Diamantino e norte das cidades de Alto Paraguai, Nortelândia e Arenápolis. Localmente, ele exibe estruturas amigdaloidais, tendo sido reconhecido como derrame vulcânico. Atinge espessura máxima de $300 \mathrm{~m}$ em sua borda ocidental, decrescendo para $50 \mathrm{~m}$ nas proximidades de Diamantino e se acunhando entre Diamantino e a 


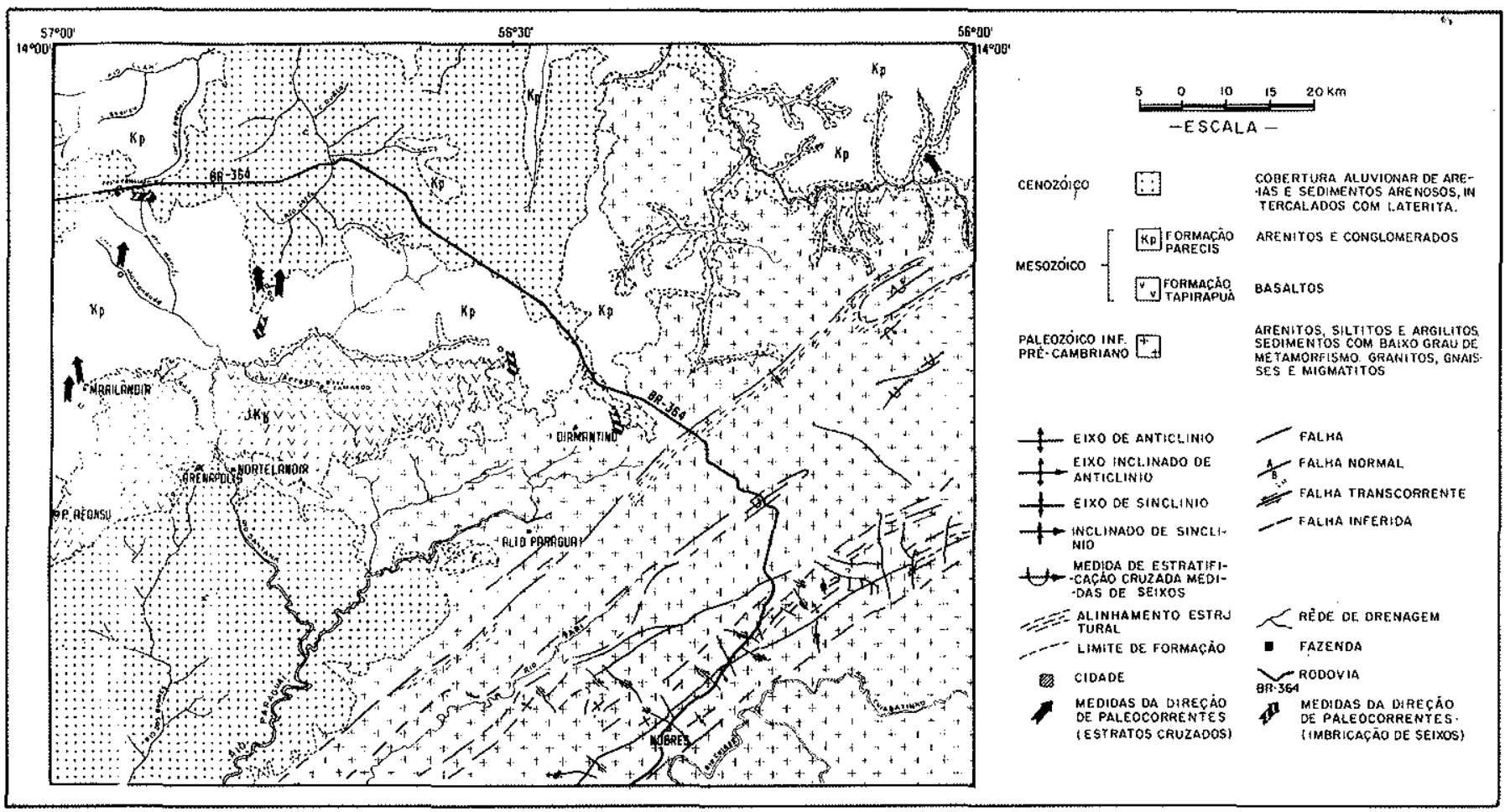

Figura 3 - Mapa geológico da Chapada Parecis, região do Rio Alto Paraguai

rodovia BR-364, quando, então, a Formação Parecis se assenta diretamente sobre o Grupo Alto Paraguai.

A idade eocretácea, determinada por métodos radiométricos, permite sua correlação com os enormes derrames basálticos da Bacia do Paraná (Fig. 1). A identificação do basalto como derrame e sua datação são de importância primordial para o estabelecimento da sucessão de eventos tectono-sedimentares que ocorreram na área.

Formaçåo Parecis O primeiro trabalho sobre a cobertura arenosa da Chapada dos Parecis foi de autoria de Vogel (1893). A Formação foi, contudo, delienada pela primeira vez por Oliveira (1915). Almeida (1964) considerou a possibilidade de que esta Formação pudesse ser um prolongamento da Formação Bauru da Bacia do Paraná, de idade neo-cretácea. Conglomerados que afloram ao longo da rodovia que liga Diamantino à BR-364 foram colocados por Almeida (op. cit.) na base da Formação Parecis. Contudo, uma idade mais nova, cenozóica, é sugerida pelas medidas de paleocorrentes (Fig. 3).

As melhores exposiçōes desta Formaç̃o situam-se entre Nortelândia e a Fazenda Camargo. A Fig. 4 reproduz uma seção geológica SW-NE, nesta área, intersectando o Basalto Tapirapuã e a Formação Parecis. O contato entre essas duas formações localiza-se próximo ao Rio Santana. Neste local, a Formação Parecis se inicia com um siltito grosseiro avermelhado, mal selecionado, com diâmetro médio dos grãos da ordem de $0,031 \mathrm{~mm}$. Subordinadamente, ocorrem camadas de arenitos bem selecionados, com diâmetro médio dos grãos de $0,100 \mathrm{~mm}$.

Arenitos muito finos a finos constitui a principal litogia da Formação na área estudada (Fig. 3). Os sedimentos mais argilosos são constituídos por siltitos de granulação média (Fazenda Camargo) a grossa (margem esquerda do Rio Arinos), em leitos aparentemente maciços.
Toda a parte inferior da Formação, pelo menos nas exposiçðes da parte média da frente da escarpa da Chapada dos Parecis, é constituída por sedimentos de granulação fina. A parte superior, exposta próxima ao topo da escarpa (Fig. 4), contém diversos níveis de conglomerados comumente associados a estruturas de e vavação e preenchimento irregularmente distribuidas. Os conglomerados que preenchem os canais possuem seixos de 10 a $20 \mathrm{~cm}$ de diâmetro. Pequenas lentes arenosas, com espessuras de ordem de $4 \mathrm{~mm}$, ocorrem dentro dos conglomerados. As camadas conglomeráticas são separadas por leitos de siltitos e arenitos finos, contendo grânulos esparsos fortemente silicificados. Os leitos conglomeráticos possuem espessuras variáveis, de 15 a $80 \mathrm{~cm}$, e os siltitos e arenitos intercalados, espessuras variáveis de 80 a $130 \mathrm{~cm}$. Os conglomerados, portanto, aparecem como leitos descontínuos, havendo também esparsos afloramentos isolados.

Acima dos conglomerados ocorrem corpos de arenitos finos e muito finos, em forma de cunha, com estratificações cruzadas, de acordo com Correa e Couto (1972). A Formação, no território de Rondônia, de acordo com Oliveira (1969), inicia-se com leitos argilosos passando, para cima, para os arenitos parecis típicos. Segundo esse autor, ao longo da rodovia BR-29, entre os quilômetros 32 e 40, ao sul do Rio Barão de Melgaço, os leitos argilosos basais contêm grande número de seixos ou mesmo matacoes de gnaisses caoticamente distribuídos. Esta litologia foi interpretada como o resultado de corridas de lamas.

Almeida (1964) silencia sobre o possivel ambiente gerador da Formação de Parecis. Contudo, tendo em vista que ele a correlacionou com a fácies não-calcária da Formação Bauru, ele implicitamente atribuiu origem fluvial à Formação. Vieira (1965) e Correa e Couto (1972) admi- 

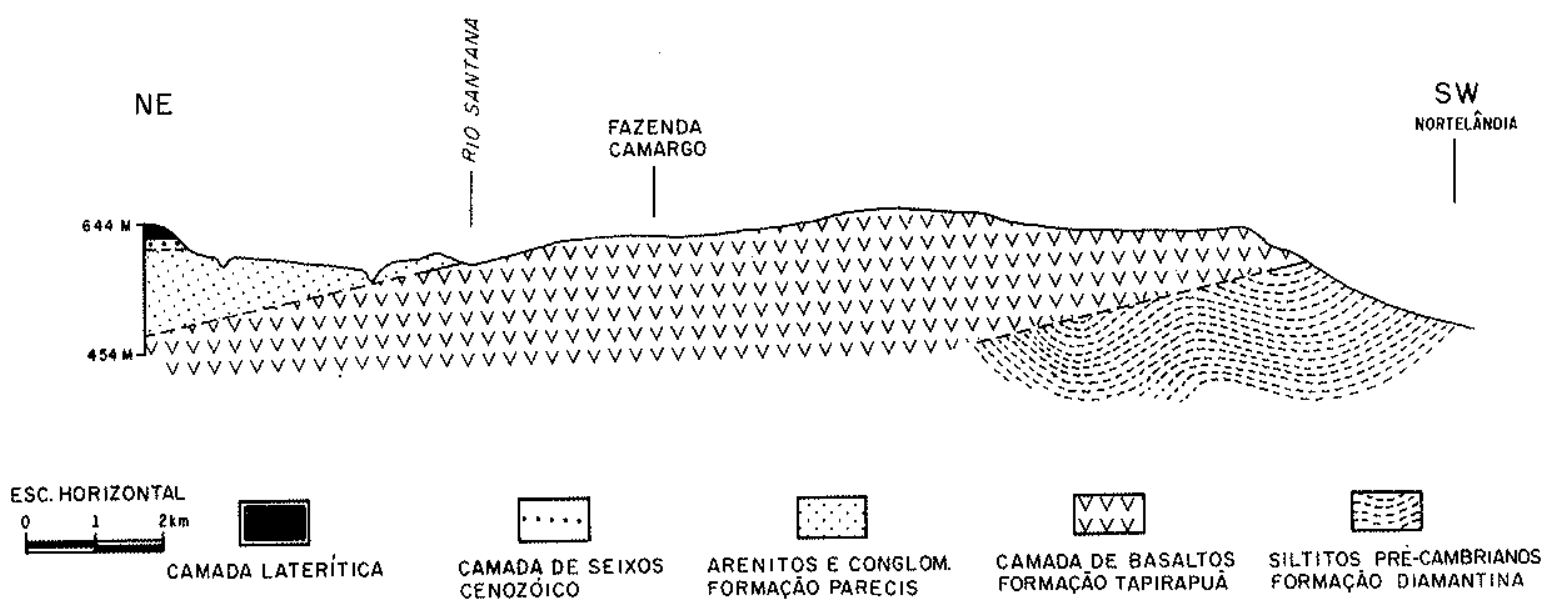

Figura 4 - Perfil geologico da Chapada do Parecis, Esiado do Mato Grosso, Brasil.

tiram origem eólica. No relatório do Projeto CentroOeste, a Formação é subdividida em dois membros - um de origem eólica e outro, acima, de origem aquosa. As evidências geológicas aqui apresentadas, as análises granulométricas e as estruturas sedimentares excluem definitivamente origem eólica, pelo menos na área estudada. Esses sedimentos, realmente, possuem fortes características indicativas de ambiente fluvial, tendo sido originados em canais fluviais e em planícies de inundação. As seções estratigráficas e as descrições das ocorrências nas áreas estudadas pelos mesmos autores são também sugestivas de sedimentos depositados em ambientes aquosos, não obstante as interpretaçðes anteriores.

Medidas de direçð̋es de estratificações cruzadas em vários afloramentos resultaram em vetores dirigidos para NNW e NNE, em bases regionais. As paleocorrentes durante a sedimentaçæo Parecis, portanto, devem ter fluído para NNW e NNE, sugerindo que o depocentro da bacia estaria localizado ao norte da área estudada. Esta interpretação é consistente com a sugerida pela distribuição das espessuras da Formação, as quais aumentam para o norte até a região do sistema de falhas do paralelo $11^{\circ} 30^{\prime} \mathrm{S}$. Em Nortelândia, a Formação possui $50 \mathrm{~m}$ de espessura enquanto em Utiariti (Fig. 2) os arenitos da Formação possuem espessura de, pelo menos, $120 \mathrm{~m}$.

Depósitos Cenozóicos Almeida (1964) já tinha chamado a atenção para esses depósitos, ressaltando suas características de extensa sedimentação conglomerática disposta em forma de leque aluvial na base das escarpas de arenito Parecis. Este autor também notou a cobertura de solos arenosos sobre os basaltos da cimeira da Serra de Tapirapuã e descreveu as camadas lateríticas constituídas de nódulos vesiculares que geralmente cobrem e protegem as cimeiras da chapada. Correa e Couto (1972) chamaram-nas de "cobertura areno-laterítica", adiantando que sua espessura ultrápassa $1,0 \mathrm{~m}$. Esses autores não mencionaram os conglomerados cenozóicos que, erroneamente, interpretaram como pertencentes à Formação Parecis.

O Quaternário das formações Pantanal, Xaraiés e Guaporé, que se estendem pelas partes mais baixas dos vales das terras baixas, são de idade mais jovem que a dos depósitos cenozóicos da Chapada, de acordo com deduções baseadas na evolução geológica da área aqui apresentada.

Os conglomerados cenozóicos da Chapada formam, na realidade, cascalheiras que ocupam um degrau da frente das escarpas, situado entre os arenitos Parecis, que afloram nas encostas, e um segundo topo chato, ocupado pelos basaltos Tapirapuã. Ocorrem, também, onde se ausentam os basaltos, cobrindo, em parte, o contato direto entre as formações Parecis e Diamantino.

As cascalheiras são formadas principalmente por seixos de quartzo. Subordinadamente, comparecem quartzitos e metarenitos. Os seixos de maiores dimensoes atingem $10 \mathrm{~cm}$ de diâmetro, contudo são mais comuns os de 2 a $8 \mathrm{~cm}$. A forma esférica predomina, perfazendo cerca de $43 \%$ dos seixos. Seixos discóides constituem $26 \%$ do total e os restantes são de forma cilíndra ou de lâmina.

A forma das litossomas sugere leques aluviais, como já foi lembrado por Almeida (1964); contudo, sua distribuição, como também a gradação vertical para componentes arenosos, sugere fanglomerados de idade pósParecis.

Medidas de imbricação de seixos nos afloramentos resultaram no reconhecimento de vetores geralmente com direçðes SSW e SSE, com um vetor deduzido de afloramentos próximos a "Porto Parecis", na BR-364, dirigido para ESE.

Os depósitos areno-lateríticos são mais jovens que as cascalheiras. Estruturas de escavação e preenchimento foram observadas entre essas duas unidades em afloramentos da Fazenda Camargo. 


\section{EVOLUÇÃO TECTÔNICA E PALEOGEOGRÁFICA DU- RANTE O MESOZÓICO E O CENOZÓICO Tendo} em vista que o Basalto Tapirapuã é a única unidade precisamente datada, as relações de contato entre o basalto e a Formação Parecis revestem-se de importância primordial. O basalto possui a idade de 135 milhões de anos, de acordo com Minioli et al. (1971). É em corpo magmático básico isolado, cronologicamente correlacionado aos extensos corpos basálticos da Bacia do Paraná, distribuído em muitos derrames empilhados. Faltam dados sobre o comportamento do Basalto Tapirapuã a este respeito, mas, a julgar por sua espessura, haveria só um ou poucos derrames de distribuição areal e restrita. Ele se acunha em uma área não muito longe da cidade de Diamantino (Fig. 3). Os amplos depósitos de colúvio e algumas ocorrências das cascalheiras cenozóicas encobrem os contatos Parecis-Tapirapuã. A superfície desse contato é de natureza discordante, erosiva. Um afloramento, cerca de 2,1 km de Marilândia em direção a Afonso, poderia lançar dúvidas sobre essa discordância visto que um arenito da Formação Parecis, próximo ao contato com basalto, está fortemente fraturado e silicificado. Estudos petrográficos de seções delgadas desse arenito não revelaram, contudo, nenhum sinal de efeitos de metamorfismo de contato, como, por exemplo, dissolução parcial de grãos de quartzo e recristalizações, feições comuns em arenitos situados nas proximidades de sills e diques de diabásio na Bacia do Paraná. As rochas basálticas Tapirapuã, portanto, são consideradas derrames, baseado nas seguintes evidências: $a$ ) área de ocorrência $\left(350 \mathrm{~km}^{2}\right) ; b$ ) espessura (350 m entre Pedro Afonso e Nova Olímpia, segundo Vieira, 1965); e $c$ ) falta de evidências de metamorfismo de contato.

A Formação Parecis, portanto, deve ser mais jovem que o Basalto Tapirapuã. Oliveira (1915) noticiou a presença de troncos silicificados de dicotiledôneas em "Serra do Norte", porém trabalhos posteriores (Almeida, 1964; Hennies, 1966; Corrêa e Couto, 1972; e Projeto CentroOeste) não revelaram fósseis nessas camadas. $\mathrm{A}$ idade cretácea atribuída à Formação é baseada na correlação com o Grupo Bauru bem como em considerações sobre a evolução geológica da área.

No presente trabalho, chama-se a atenção sobre a possibilidade de correlação com a Formação Alter-do-Chão da Bacia do Amazonas. Neste caso, a correlação da Formação Parecis seria com a parte inferior do Grupo Bauru (incluindo aqui a Formação Caiuá no sentido dos autores mais modernos).

As paleocorrentes que prevaleceram durante a sedimentação da Formação Parecis eram dirigidas para NNE e NNW, deduzidas de medidas de estratificações cruzadas em arenitos da Formação. Sua espessura aumenta para o norte reforçando esta interpretação. $\mathrm{O}$ depocentro da Formação deveria localizar-se em uma área ao norte da estudada aqui. As rochas-fontes, portanto, deveriam localizar-se ao sul, na região hoje deprimida que compreende as terras baixas do Rio Alto Paraguai como também a Serra de Tapirapuã e a Província Serrana. Esta província é uma região colinosa que constitui o divisor de águas entre os rios Paraguai e Cuiabá.

A Província Serrana, constituída de sedimentos eopaleozóicos (Cambriano e Ordoviciano), não-metamorfizados mas fortemente dobrados, eleva-se $800 \mathrm{~m}$ em suas partes mais altas. Durante o cretáceo, esta província poderia ter sido ainda mais elevada e teria sido área-fonte tanto para a formação Parecis como para os sedimentos cretáceos da parte noroeste da Bacia do Paraná, pertencentes ou correlacionados ao Grupo Bauru.

Durante o Cenozóico, a atual área-limite entre bacias do Paraná e Amazonas ter-se-ia elevado em relação à velha área-fonte, iniciando, então, a modelagem do relevo atual. Os arenitos da Formação Parecis estão silicificados ao longo das zonas de fraturas e brechas, e milonitos ocorrem ao longo das falhas.

Fulfaro e Suguio (1974) propuseram uma coluna estratigráfica para o Cenozóico do Estado de São Paulo, baseados na evolução tectônica da Bacia do Paraná nesse Estado, desde o final do episódio de sedimentação do Grupo Bauru, de idade cretácea. Esses autores sugeriram que o clima reinante durante a sedimentação carbonática, que caracteriza a parte superior do Grupo Bauru, seria semi-árido. A evidência apontada para essa dedução é a interpretação de Suguio (1973), diagnosticando como caliche os nódulos calcários da parte superior do Grupo. Os autores supracitados acreditam que as mesmas condições climáticas teriam prevalecido no início do Cenozóico, baseados nas características dos depósitos que hoje estão conservados em muitos dos amplos divisores dos rios do Estado de São Paulo. Tais depósitos pós-Bauru, interpretados como do Eocenozóico, possuem características estruturais e distribuição espacial que permitem sua interpretação como fanglomerados.

As semelhanças entre a situação nos divisores de águas do Estado de São Paulo, na área onde o Grupo Bauru está presente, e na Chapada dos Parecis são tão grandes que não se pode fugir a uma interpretação análoga. O Cenozóico da Chapada possui características de fanglomerados e está situado sobre os sedimentos da Formação Parecis, cronologicamente equivalente ao Bauru. As evidências sugerem idade eocenozóica para os depósitos mais antigos do Cenozóico da Chapada.

As determinações das orientações dos seixos das cascalheiras eocenozóicas da Chapada dos Parecis resultaram no reconhecimento de vetores dirigidos para SSE e SSW. Tais vetores sugerem paleocorrentes com rumos SSE e SSW, que está de acordo com o modelo proposto.

A Província Serrana pertence a uma enorme linha estrutural que se estende da desembocadoura do Rio Amazonas à região de Assunção, no Paraguai. A direção desta linha, da foz do Amazonas à região estudada, é N-S. Daí ela curvar-se para WSW, bordejando a Chapada dos Parecis, curvando-se depois, novamente para o sul, atingindo o Paraguai, onde é chamada de Arco Central Paraguaio (Putzer, 1962) ou Arco de Assunção (Lange e Petri, 1967). Este arco foi a fonte ocidental para os sedimentos da bacia do Paraná durante o Paleozóico e o Mesozóico, quando, então, constituía-se em terras elevadas. Um tectonismo que ocorreu há cerca de 46 milhões de anos causou a subsidência do arco. Essa idade foi deduzida pelas datações radiométricas de rochas básicas, ricas em nódulos de olivina, provenientes do manto, intrusivas ao longo de planos de falhas da fossa tectônica de Ipacaraí no Paraguai (Stormer et al., 1975). Essa fossa ocupa parte do espaço geográfico do Arco Paraguai Central. As terras baixas do Pantanal Mato-grossense constituemse na extensão natural, para o norte, da região paraguaia 
tectonicamente deprimida e, portanto, a mesma idade pode ser atribuída a elas e aos movimentos diferenciais que causaram o desenvolvimento da Chapada dos Parecis.

No mapeamento geológico da área do Rio Aporé, na divisa do Estado de Goiás com Mato Grosso do Sul, no Parque Nacional das Emas, foi constatado que os sedimentos do Grupo Bauru estão falhados e, no interior das depressões, assentam-se os sedimentos Terciários da Formação Cachoeirinha, indicando sua origem a partir dos altos formados pelo falhamento pós-Bauru.

O modelo de eventos geológicos proposto é ilustrado na Fig. 5. A situação geológica reinante durante o neocretáceo e o eocenozóico até 46 milhôes de anos atrás desapareceu, dando lugar ao desenvolvimento da Chapada e dos depósitos de cascalheiras, atingindo-se, gradualmente, a presente topografia.

CONCLUSÕES Os conglomerados da Formação Parecis, borda da Chapada, são diamantíferos (Petri e Fulfaro, 1975). Sucessivos retrabalhamentos concentraram os diamantes nas cascalheiras cenozóicas e, finalmente, nos aluvioes recentes e sub-recentes dos rios da Bacia do Paraguai, onde estão sendo explorados. De acordo com o modelo proposto, as rochas diamantíferas primárias seriam encontradas ao sul da Chapada dos Parecis, na área do Pantanal Mato-grossense tectonicamente rebaixada. Essa área atualmente está coberta por sedimentos cenozóicos que atingem, em alguns lugares, $350 \mathrm{~m}$ de espessura, revelados por sondagens. As supostas rochas magmáticas diamantíferas primárias, portanto, não aflorariam.

Intensos movimentos tectônicos têm sido freqüentemente notados no Brasil Sul e Sudeste. Quando este tectonismo atingiu seu clímax, as fossas de Santos e Pelotas, na atual plataforma continental, estavam em fase de máxima subsidência e a Serra do Mar, adjacente, em fase de máxima elevação. A Chapada dos Parecis e terras baixas adjacentes poderiam ter tido história similar. $O$ vale do Rio Paraíba, estendendo-se através dos Estados de São Paulo e do Rio de Janeiro, é um vale tectônico de afundamento. Falhamentos em bloco, de idade miocênica (ou neo-oligocênica) representam a drenagem, resultando em diversas bacias sedimentares isoladas, como as de São Paulo, Taubaté, etc. (Fulfaro, 1974). Esta fase da reativação Wealdeana (Almeida 1967) deve ter sido a responsável pelo desenvolvimento da Chapada dos Parecis.

A paleogeografia e o arcabouço tectônico que condicionaram a deposição dos sedimentos da Formação Parecis sugerem a presença de ampla bacia sedimentar dentro do Cráton de Guaporé, com depocentro localizado em uma região hoje ocupada por afloramentos de rochas eopaleozóicas e pré-cambrianas. Movimentos tectônicos cenozóicos nesse cráton teriam levantado os sedimentos cretáceos causando sua subseqüente remoção por erosão. Sugere-se aqui o planejamento de futuras pesquisas no sentido de comparar os sedimentos da Formação Parecis com os sedimentos cretáceos da Formação Alter-doChão, da Bacia do Amazonas.

Agradecimentos À Fundação de Amparo à Pesquisa do Estado de São Paulo (FAPESP), pelo auxílio concedido para os trabalhos de campo. Ao Conselho Nacional de Desenvolvimento Científico e Tecnológico (CNPq), pelo financiamento de viagem com a finalidade de apresentar o trabalho do XXV Congresso Internacional de Geologia, realizado na Austrália. À Companhia de Desenvolvimento de Mato Grosso e a seu geólogo Giancarlo Lastoria, pelo fornecimento de veículo durante parte de nossos trabalhos de campo, e à pós-graduanda Maria Helena Zucon, do Instituto de Geociências da USP, pelas análises de laboratório.

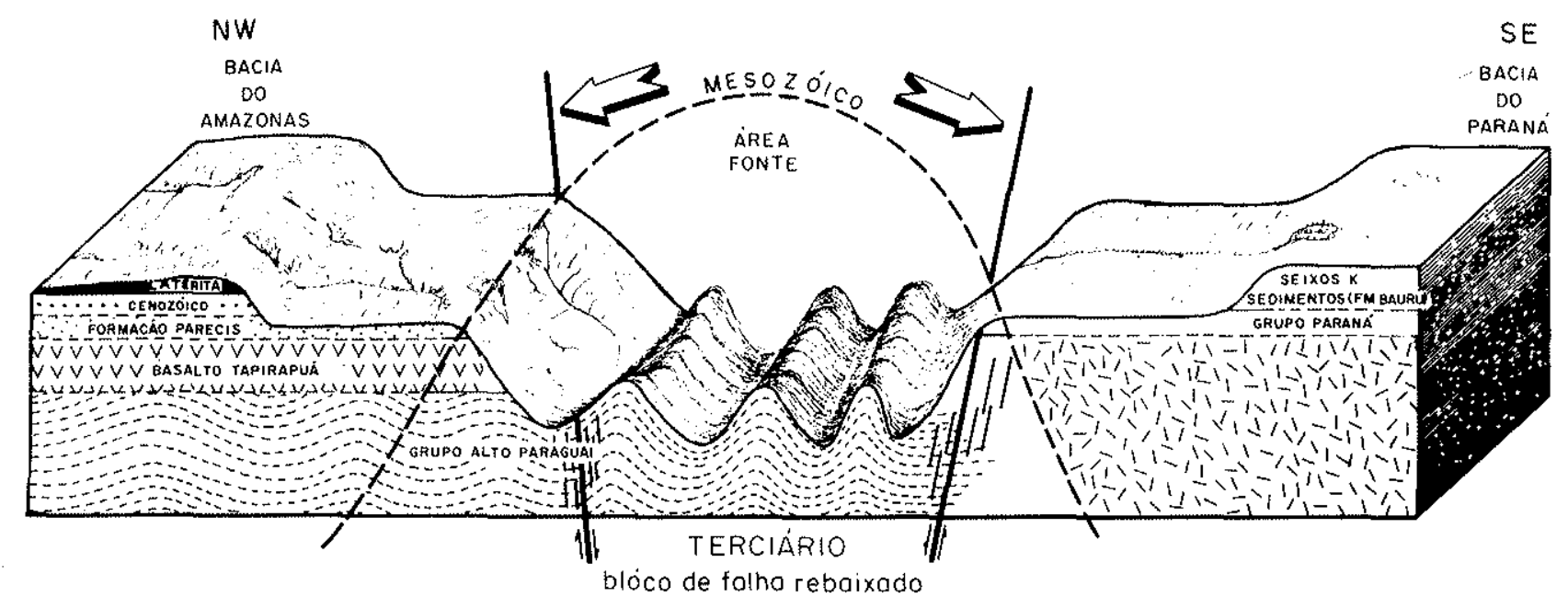

Figura 5 - Evolução tectônica mesozóicancenozóica da regiãoida Chapáda dos Parecis 


\section{BIBLIOGRAFIA}

AB'SABER, A. N. - 1954 - O Planalto dos Parecis na região de Diamantino (Mato Grosso), Rev. Paul. Geogr. n: 17:63-79. Săo Paulo.

AMARAL, G. w 1974 - Geologia pré-cambriana da regiăo amazónica, Inédito. Tese de Livre-Docência na Univ. de Săo Paulo. Săo Paulo.

ALMEIDA, F. F. M. de - 1964 - Geologia do Centro-Oeste Matogrossense, Brasil. Div. Geol, Min., n. 215:134 pp. Rio de Janeiro.

ALMEIDA, F. F. M. de - 1967 - Origem e evoluçăo da plataforma brasileira, Brasil. Div. Geol. Min., n: 241:36 pp. Rio de Janeiro.

CASTELNAU, F. de - 1850, 1851, 1852 - Expedition dans les parties centrales de l'Amérique du Sud - Histoire du voyage: Tome Il (1850): 485 pp.; Tome III (1851):483 pp.; Itinéraires et coupe géologique, part IV (1852). P. Bertrand Libraries ed, Paris.

CORREA, J. A. e COUTO, E. A. do - 1972 - Projeto Aluviðes: Brasil. Dep. Nac. Prod. Min. e CPRM. Inédito. Goiânia.

CPRM - 1975 - Projeto Centro-Oeste de Mato Grosso: Brasil. Dep. Nac. Prod. Min. e CPRM. Inédito. Goiânia.

EVANS, J. W. -1894 - The geology of Mato Grosso (particulary the regions drained by the upper Paraguay). Geol. Soc. London., Quart. Jour. $50(2): 85-104$. Londres.

FULFARO, V. J. - 1974 - Tectônica do alinhamento estrutural do Paranapanema. Bol. Inst. Geoc., Univ, de São Paulo, 5:129-138. Săo Paulo.

FULFARO, V. J, e SUGU1O, K. - 1974 - O Cenozóico paulista: gênese e idade. XXVIII Congr. Bras. Geol, An., vol. 3, pp. 91-102, Porto Alegre.

GUIMARÃES, D. $-1971-\mathrm{O}$ arenito Parecis e sua posiçăo crono-geológica, Brasil. Div. Geol. Min. Not. Prel. e Est., n? 150:3-6. Rio de Janeiro.

HENNIES, W. T. - 1966 - Geologia do Centro-Oeste Matogrossense. Inédito. Tese de Doutoramento na Univ. de São Paulo. Såo Paulo.

LANGE, F. W, e PETRI, S. - 1967 - The Devonian of the Paraná Basin: Problems in Brazilian Devonian Geology. Bol. Paran. Geo, 21/22:5-61.

MINIOLI, B., PONÇANO, W. L. e OLIVEIRA, S. M. B. - 1971 - Extensão geográfica do vulcanismo basáltico do Brasil Meridional. An, Ac. Bras. Ciên. 43(2):433-437. Rio de Janeiro.
OLIVATTI, O. - 1980 - Projeto Paulipetro, Relatório Final Bloco 70. Comp. Pesq. Rec: Min. CPRM - Superintendência Regional de Goiânia, Inédito.

OLIVEIRA, E. P. - 1915 - Geologia, reconhecimento geológico do Noroeste de Mato Grosso. Expediçăo Cientifica Roosevelt - Comissăo Rondon de $\mathrm{Li}$ nhas Telegráficas - Estado de Mato Grosso - Anexo 1. 82 pp. Rio de Janeiro.

OLIVEIRA, M. A. M. - 1964 - Reconhecimento geológico expedido do Alto Paraguai. Petrobrás. Inédito. Ponta Grossa.

PETRI, S e FULFARO, V. J. - 1975 - O arcabouço geológico do diamante do Centro-Oeste de Mato Grosso. II Congr. Ibero-Americano de Geol. Econ Res. Comunicações. Buenos Aires.

PUTZER, H. $-1962-$ Geologie von Paraguay. Beitr. z. Reg. Geol, der Erde. Band. 2-Gebruder Bornt. Berlin Nikol. 182 pp.

STORMER, J. C., GOMES, C. B. e TORQUATO, J. R. F. - $1975 \mathrm{~m}$ Spinel Iherzonite nodules in basanite lavas from Asunción, Paraguay. Rev. Bras. Geoc. 8:176-185.

SOARES, P. C., LANDIN, P. M. B., FULFARO, V. J. E SOBREIRO NETO, A. F. - 1980 - Ensaio de Caracterização estratigráfica do Cretáceo no Estado de Săo Paulo: Grupo Bauru. Rev. Bras. Geoc. 10(3): 177-185.

SUGUIO, K. - 1973 - A Formaçáo Bauru: Calcátios e sedimentos detríticos as sociados. Inédito. Tese de Livre-Docência da Univ. de Sð̌o Paulo. Sð̋o Paulo.

VIEIRA, A, F. - 1965 - Geologia do Centro-Oeste de Mato Grosso. Petrobrás, n: 303, Inédito. Ponta Grossa.

VOGEL, P. - 1893 - Reisen in Mato Grosso $1887 / 1888$ (Zweite SchinguExpedition). Gessels-f-Erdk. z. Berlin, Zeitschr. B. XXVIII, S. 243-352. Berlin. 